\title{
Non-Receptor Tyrosine-Protein Kinase TNK1
}

National Cancer Institute

\section{Source}

National Cancer Institute. Non-Receptor Tyrosine-Protein Kinase TNK1. NCI Thesaurus.

Code C30114.

Non-receptor tyrosine-protein kinase TNK1 (666 aa, $72 \mathrm{kDa}$ ) is encoded by the human

TNK1 gene. This protein plays a role in tyrosine phosphorylation, the negative regulation of cell growth and tumor suppression. 